\title{
Effect of TEA on the structural and magnetic properties of ferromagnetic $\mathrm{ZnFe2O4}$ nanoparticles
}

\begin{abstract}
Ferromagnetic $\mathrm{ZnFe} 2 \mathrm{O} 4$ nanoparticles were synthesized by surfactant assisted hydrothermal method using different amount of triethylamine (TEA). The synthesized nanoparticles were characterized by powder X-ray diffraction, Fourier transform infrared spectroscopy, field emission scanning electron microscopy, transmission electron microscopy (TEM), highresolution transmission electron microscopy and vibrating sample magnetometer. The formation of single phase $\mathrm{ZnFe} 2 \mathrm{O} 4$ was investigated by addition of different amount of TEA. Regular spinel structure was obtained for all synthesized product except for lower amount of TEA, owing to the less alkaline atmosphere. All the synthesized nanoparticles were spherical in shape with a small aggregation. Observed size of the nanoparticles was $10 \mathrm{~nm}$ as determined from TEM measurement for the sample synthesized with a higher amount of TEA. Room temperature ferromagnetic behavior was observed in all the samples.
\end{abstract}

Keyword: Ferromagnetic $\mathrm{ZnFe} 2 \mathrm{O} 4$ nanoparticles; TEA 